\title{
Classical conditioning of vocalizations in the rat: Acoustic characteristics of the CR and UCR
}

\author{
WERNER NITSCHKE \\ Luther College, Decorah, Iowa 52101
}

\begin{abstract}
Classically conditioned shock-elicited vocalizations in the adult rat were acoustically analyzed and described. The fundamental frequency of the CRs ranged between 2,000 and $3,600 \mathrm{~Hz}$, with overtones that extended well into the ultrasonic range and with durations lasting approximately $1 / 2$ sec. Major differences between $C R$ and UCR signals were apparent. The CR vocalizations had little frequency variation and little or no noise, while the UCR vocalizations were associated with highly irregular frequencies and broad-band noise. Postshock vocalizations had combined features of the CR and UCR sounds. It is suggested that the differences between the CR and UCR are related to the CR being the emotional cry and the UCR the pain cry.
\end{abstract}

A great deal of research has been conducted on the acoustic characteristics of rodent vocalizations. Most of these studies have been associated with the production of ultrasounds by infant and adult rodents and have been summarized by Nitschke, Bell, and Zachman (1972), Noirot (1972), Sales (1972), and Sales and Pye (1974). The few studies of Pavlovian conditioning of vocal behavior that have been conducted typically report the number of vocalizations emitted to a CS (Warner, 1932; Schlosberg, 1934, Cowles \& Pennington, 1943; Davis \& Hubbard, 1973). Not reported are the signal's frequency (hertz), duration, intensity, and complexity of waveforms (whether pure tone, frequency sweeps, or shifts).

Davis and Hubbard (1973), in their review of earlier attempts to condition shock-elicited vocalizations, indicate that some experimenters have been unable to obtain a vocal response to the CS. They suggest, as did Mowrer, Palmer, and Sanger (1948), that stable CRs may be obtained only if the rat is immobilized in a restraining device. Davis and Hubbard also suggested that vocal behavior may be conditioned only when no competing speciesspecific defense reactions (SSDRs) are available to the subject. These researchers have examined the mobility of the rat and the variability of the intertrial interval (ITI) during conditioning and report that, although a fixed or variable ITI was not a critical factor for classical conditioning of vocal behavior, immobilization was crucial. The present

The author is grateful to Madison Dengler, Harlan Sanderson, Mark Marnocha, Dan Nelson, Diane Nitschke, and Janet Hemesath for technical assistance. A portion of the equipment used in this investigation was obtained by Grant SER 77-12069 from the National Science Foundation. study extends the work on Pavlovian conditioning of vocalizations in the laboratory rat by providing an acoustic analysis of those sounds emitted during the training procedure. Signals identified as UCRs and CRs were measured and compared to the rat's repertoire of vocal behaviors. Although pilot data indicated that the overtones of $C R$ vocalizations extend well into the ultrasonic range, the primary interest of this study was to specify the fundamental signal, which is sonic.

\section{METHOD}

\section{Subjects}

Eight experimentally naive male Hoitzman rats, 100-190 days of age, were used as subjects. They were housed individually and maintained on ad-lib food and water.

\footnotetext{
Apparatus

Vocalizations were recorded on a Hewlett-Packard 3964A four-channel instrumentation recorder, using a direct recording procedure with a tape speed of 2.38 or $38.20 \mathrm{~cm} / \mathrm{sec}$. A Maxell $35-$ 90 polyester-base 1.0-mil tape was used. The transducers employed were a Brüel and Kjaer 4133 free-field condensor microphone with a 2619T cathode follower connected to a Bruel and Kjaer 2608 microphone amplifier.

The restraining device was constructed from a $7.6-\mathrm{cm}$-diam $x$ 25.4-cm-long metal canister. Parallel to the front face of the can and $11.4 \mathrm{~cm}$ from that face a cut was made half way through the canister. The cut continued $90^{\circ}$ to this edge, alone the midplane of the cylinder to $1.9 \mathrm{~cm}$ from the bottom face, and then continued parallel to the rear face through the remainder of the can. A $1.6 \times 3.8 \mathrm{~cm}$ opening was cut out of the bottom face in order to expose the rat's tail, and a fine wire-mesh screen cover was placed over the front opening of the can. Along each cut edge of the can, a bead of solder was placed and then heavily taped to prevent injury on these surfaces. The inside diameter was made adjustable to individual subjects through the utilization of a $5.1-\mathrm{cm}$-wide cardboard liner positioned in the front cylinder, while the length was made adjustable by overlapping the two cylinder sections. Once the subject was placed in this device, both
} 
Table 1

Number of CRs Occurring During Each Day for Rats in Paired and Unpaired Stimulus Conditions

\begin{tabular}{lccc}
\hline Stimulus & & & \\
Condition & Day 1 & Day 2 & Day 3 \\
\hline Paired & 52 & 231 & 216 \\
Unpaired & 2 & 9 & 1 \\
\hline
\end{tabular}

cylinder sections were taped together and then suspended from a stand.

Electric shock was generated by a Lafayette Model 5226 shocker and delivered through copper wire electrodes wrapped around the subject's tail. Shock was set at $3.0 \mathrm{~mA}$ for a $1.0-\mathrm{sec}$ duration.

A test chamber was constructed out of composition board and foam rubber in order to control lighting and attenuate ambient noise. The outside walls of the box were $65 \times 70 \times$ $72 \mathrm{~cm}$ high, while the inside space measured $30 \times 32 \times 41 \mathrm{~cm}$ high. The stand which held the restraining device and the microphone was placed inside the chamber and positioned directly in front of a $71 / 2$-W light source. All of the other equipment, including three Hunter timers which timed CS, UCS, and ITI durations, were outside the chamber, as was a telegraphic key which was activated with the onset and offset of the CS. The click sound made by the telegraphic key functioned as a sonic marker for the light CS and was recorded along with the vocalizations on another channel. The characteristics of the vocalizations were analyzed on a sonagraph (Kay Elemetrics Model 6061B).

\section{Procedure}

Four subjects were assigned to a paired stimulus condition in which the CS (light) was presented for $4.0 \mathrm{sec}$ and was followed immediately by the UCS (shock) for a 1.0 -sec duration. A total of 20 paired presentations of CS-UCS per daily session was given for 3 consecutive days. Extinction trials (by UCS removal) immediately followed the last training session and were continued until 20 consecutive no-vocal responses were recorded. The four control subjects were assigned to an unpaired stimulus condition in which a random sequence of 40 trials per day was used for each subject, with a trial consisting of presentation of either the CS or the UCS alone. An equal number of CS and UCS trials were used. Durations of the CS and UCS were identical to the paired presentation, and the ITI for both groups was fixed at $75 \mathrm{sec}$.

The instrumentation recorder was on continuously throughout all sessions, with the tape speed set at $2.38 \mathrm{~cm} / \mathrm{sec}$. However, $25 \%$ of the sessions were taped at a higher speed $(38.10 \mathrm{~cm} / \mathrm{sec})$ to extend the recording into the ultrasonic range. In order to conduct sonagraphic analysis of ultrasounds, the instrumentation recorder was slowed down to $9.52 \mathrm{~cm} / \mathrm{sec}$, thereby expanding the time base and reducing the frequencies by one-quarter of their actual value.

\section{RESULTS}

A CR was defined as any vocalization that occurred within $4 \mathrm{sec}$ after the onset of the CS. The total number of CRs produced in the paired and unpaired stimulus conditions for each day is presented in Table 1 . There was a significantly greater number of CRs produced under the paired condition compared to the unpaired condition for all days tested $[F(1,6)$ $=21.958, \mathrm{p}<.01]$. It can also be seen that the rats in the unpaired condition emitted only a few CR vocalizations each day, while the subjects in the paired condition dramatically increased their CRs from Day 1 to Days 2 and 3, $[F(2,12)=12.680, p<.01]$.

The number of sonagraphs made from randomly selected vocalizations were: 109 CRs, 24 UCRs, 32 postshock signals, and 6 extinction responses. Each signal was measured for its frequency, duration, and latency to the CS onset (if it was the first CR in a trial).

\section{CRs}

Table 2 presents the mean characteristics of the vocalized CRs obtained from sonagraphs for the paired group. The differences between subjects for signal frequency was significant $[F(3,105)=44.770$, $\mathrm{p}<.01$ ]. Tukey's HSD test was used to make additional comparisons between each pair of frequency means, and it indicated that several means differed significantly at the $\mathrm{p}<.01$ level. The fundamental frequency of these signals ranged between 2,000 and $3,600 \mathrm{~Hz}$, with overtones that extended past $50 \mathrm{kHz}$. The mean duration of $C R$ vocalizations did not differ between subjects $[F(3,105)=.1763, \mathrm{p}>.05]$, but the durations between the first signal in a series of CRs was significantly longer $(p<.01$ level) for all subjects than the average of those signals that followed.

During the extinction phase, Subjects 1, 2, 3, and 4 took $3,2,1$, and 5 trials, respectively, before 20 consecutive trials of no vocalizations occurred. The signals emitted and sampled during this period were too few for statistical analysis, but sonagraphs made of these extinction vocalizations appeared to be indistinguishable from acquisition CR signals.

Table 2

Mean Characteristics of Vocalized CRs

\begin{tabular}{|c|c|c|c|c|c|c|}
\hline \multirow[b]{2}{*}{ Subject } & \multicolumn{2}{|c|}{ Fundamental Frequencies (Hertz) } & \multirow{2}{*}{$\begin{array}{l}\text { Duration of All } \\
\text { Signals* }\end{array}$} & \multicolumn{2}{|c|}{$\begin{array}{l}\text { Duration of Signals Given } \\
\text { in a Series During a Trial }\end{array}$} & \multirow{2}{*}{$\begin{array}{l}\text { Latency to } \\
\text { First CR* }\end{array}$} \\
\hline & Frequency & SD & & First & Secondary & \\
\hline $\begin{array}{l}1 \\
2 \\
3 \\
4\end{array}$ & $\begin{array}{l}2857 \\
2351 \\
2776 \\
2983\end{array}$ & $\begin{array}{l}177.28 \\
136.91 \\
253.77 \\
268.44\end{array}$ & $\begin{array}{l}.552 \\
.536 \\
.492 \\
.519\end{array}$ & $\begin{array}{l}.599 \\
.702 \\
.579 \\
.586\end{array}$ & $\begin{array}{l}.385 \\
.441 \\
.385 \\
.401\end{array}$ & $\begin{array}{l}.480 \\
.787 \\
.496 \\
.681\end{array}$ \\
\hline
\end{tabular}

Note-Fundamental frequencies of all subjects except Subjects 1 and 3 were significantly different from each other (all ps $<.01$ ). Comparisons of duration of first signal and durations of secondary signals were significant for each subject (all ps $<.001)$.

*In seconds. 


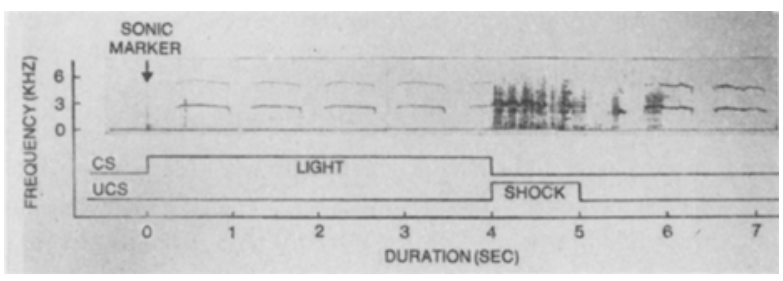

Figure 1. A series of overlapping sonagraphs showing the following acoustic information: a sonic marker made by instrumentation at the onset of the CS, four complete CRs with their harmonics, one CR in transition to the UCR, and a few postshock vocalizations.

\section{CRs, UCRs, and Postshock Vocalizations}

Figure 1 shows a series of sonagraphs that were overlapped to depict a 7.2-sec sequence in which the ISI is shown. The differences between the CR vocalizations and the UCR vocalizations are typical. In every case, the vocalized UCR is associated with broadband noise in addition to several signals which are short in duration and have rapid frequency shifts. The CR vocalizations have little or no noise component, usually have very stable frequencies, and are not as intense as UCR sounds. The postshock vocalizations, however, often have components of both the CR and UCR signals. It can be seen in Figure 1 that after the shock terminates, the noise components of the UCR continues momentarily and then stabilizes to a more singular frequency similar to the CRs. UCRs and postshock vocalizations were recorded on every trial. Postshock vocalizations were rarely observed $30 \mathrm{sec}$ after shock offset.

\section{Incidental Observations}

It was noticed that the frequency of the $C R$ signais appeared similar to the squeak that many rats make when first handled. On occasion, these sounds were heard and recorded when the rats were first placed in the restraining device. Analysis of these "handled" sounds showed them to be markedly similar to the frequencies of the CR and postshock vocalizations, but they were approximately $.3 \mathrm{sec}$ in duration.

\section{DISCUSSION}

The results from this study describe many of the acoustic characteristics of classically conditioned vocalizations in the adult rat. It was found that the fundamental CR frequency for the rats in this experiment ranged between 2,000 to $3,600 \mathrm{~Hz}$ with so little within-subject variance that it was often possible to identify the individual on the basis of frequency alone. Each fundamental signal was also associated with a series of overtones that continued well into the ultrasonic range. With the onset of the UCS (shock), the vocal response changed considerable. The CR signal could be characterized as being quite stable in frequency, long in duration, with little or no noise associated with it. UCR vocalizations, in contrast, shifted erratically up and down in frequency, often had a series of shorter duration pulses which closely followed one another, and were always associated with broadband noise. These different features, which were easily discriminable on the sonagraph, were also easily differentiated by ear, and appeared to clearly distinguish the emotional cry (CR) from the pain cry (UCR).

The number of CRs obtained in this study was considerably greater than that reported by Davis and Hubbard (1973). The ISIs for both studies were identical, and since only a slightly shorter ITI was used by Davis and Hubbard (60 sec compared to $75 \mathrm{sec}$ ), it is likely that the much stronger UCS used in the present study ( $3 \mathrm{~mA}$ compared to $.8 \mathrm{~mA}$ ) was responsible for the greater number of CRs. However, since Davis and Hubbard (1973) had vocalizations fed through an acoustic filter set at $3,200 \mathrm{~Hz}$ (higher than the mean vocalizations obtained in this study) and then relayed to an event recorder, it is possible that some of the lower frequency CRs were filtered out.' Another difference between the two studies was associated with the type of restraining device used. Davis and Hubbard (1973) argued that the canister type of restraint utilized by Herbert (1946) and in this study might permit the occurrence of SSDRs, i.e., freezing behavior, which might interfere with obtaining conditioned vocalizations. Such a SSDR presumably does not occur with an open sling, where the subject's feet hang below the sling. It might just as well be argued, however, that although an open sling prevents freezing behavior it does not prevent the leg motion used in running which is a SSDR inhibited in the canister.

The fundamental signal of the emotional cries reported in this study was sonic and stands in contrast to the commonly observed ultrasonic vocalization produced by rodents within a social context, i.e., aggression, copulation, and submission (Sales \& Pye, 1974). Since infant rodents produce ultrasound under cold stress (Nitschke et al., 1972), additional work is needed to determine if stress-elicited sonic vocalizations obtained under classical conditioning with adults are age related or stimulus related. The shock used in this study is tactile in nature. Other tactile stimulation considered to be painful for infant mice, such as pinching the scruff of the neck and tapping the tail, have been reported by Okon (1970) to elicit ultrasonic signals accompanied by sonic cries. Since Okon (1970) did not record the introduction of the stress stimulus along with the animal's vocalizations as was done in this study, it is difficult to determine if a relationship existed between a particular type of vocalization and a specified procedure, e.g., pinching, handling, or cooling. 


\section{REFERENCES}

Cowles, J., \& Pennington, L. An improved conditioning technique for determining auditory acuity of the rat. Journal of Psychology, 1943, 15, $41-47$.

Davis, H., \& HubBard, J. Conditioned vocalization in rats. Journal of Comparative and Physiological Psychology, 1973, 82, 152-158.

Herbert, M. An improved technique for studying the conditioned squeak reaction in hooded rats. Journal of Genetic Psychology, $1946,34,67-77$.

Mowrer, O., Palmer, F., \& Sanger, M. Individual learning and "racial experience" in the rat with special reference to vocalization. Journal of Genetic Psychology, 1948, 73, 29-43.

Nitschke, W., Bell, R. W., \& Zachman, T. A. Distress vocalizations of young in three inbred strains of mice. Developmental Psychobiology, 1972, 5, 363-370.

NoIRot, E. Ultrasounds and maternal behavior in small rodents. Developmental Psychobiology, 1972, 5, 371-387.

OKon, E. E. The ultrasonic responses of albino mouse pups to tactile stimuli. Journal of Zoology, London, 1970, 162, 485-492.
SAlEs, G. D. Ultrasounds and aggressive behavior in rats and other small rodents. Animal Behaviour, 1972, 20, 88-100.

SAles, G., \& PYe, D. Ultrasonic communication by animals. London: Chapman and Hall, 1974.

Scholosererg, H. Conditioned responses in the white rat. Journal of Genetic Psychology, 1934, 45, 303-335.

Warner, L. H. An experimental search for the "conditioned response." Journal of Genetic Psychology, 1932, 41, 91-115.

\section{NOTE}

1. It was also indicated that the setting on the acoustic filter was lowered to $500-600 \mathrm{~Hz}$ during the course of monitoring the subject's performance. Depending on the selectivity of their acoustic window, a number of CRs could have been filtered out.

(Received for publication January 29, 1979; revision accepted April 20, 1979.) 